\title{
Cogestão e processo de intervenção de apoiadores da Política Nacional de Humanização (PNH)
}

Daniela Baumgart de Liz Calderon ${ }^{(a)}$

Marta Inez Machado Verdi(b)

Calderon DBL, Verdi MIM. Comanagement and the intervention process of supporters of the National Humanization Policy (PNH). Interface (Botucatu). 2014; 18 Supl 1:859-70.

The aim of this study was to analyze the changes in management methods generated through the intervention process by institutional supporters who underwent training through the institutional supporters' course for Humanization of Brazilian Health System (SUS) Care and Management, in Santa Catarina, Brazil, in 2009. This was a qualitative study with a descriptive and exploratory design. The research subjects comprised seven institutional supporters who worked on the "comanagement" guideline in their intervention plans. The data-gathering consisted of document research and interviews. The data analysis used the hermeneutic dialectic method, with classification and grouping into thematic categories: "Motivation for comanagement work", "Experimenting with comanagement" and "Effects of Intervention." The results showed that the movements triggered by interventions from supporters in services, with regard to comanagement, were important for promoting changes in processes that previously had been set in stone, although many challenges still remain.

Keywords: Brazilian Health System. Healthcare management. Brazilian Humanization Policy. Comanagement.
O objetivo deste estudo foi analisar as mudanças nos modos de gestão geradas pelo processo de intervenção dos apoiadores institucionais formados no Curso de Apoiadores Institucionais para a Humanização da Atenção e Gestão do Sistema Único de Saúde (SUS) em 2009, em Santa Catarina, Brasil. Tratase de uma pesquisa do tipo qualitativa, com design exploratório-descritivo. Os sujeitos de pesquisa foram sete apoiadores institucionais que trabalharam a diretriz "cogestão" em seus planos de intervenção. A coleta de dados se deu por meio de pesquisa documental e entrevistas, sendo analisados por meio do método hermenêutico dialético. Eles foram categorizados e reagrupados em categorias temáticas: "Motivações para trabalhar cogestão", "Experimentando a cogestão" e "Efeitos da intervenção". Os resultados indicam que os movimentos disparados pelas intervenções dos apoiadores nos serviços com relação à cogestão foram importantes para promover mudanças em processos anteriormente cristalizados, entretanto inúmeros desafios ainda permanecem.

Palavras-chave: Sistema Único de Saúde. Gestão em Saúde. Política Nacional de Humanização. Cogestão.

\footnotetext{
(a) Secretaria

Municipal de Saúde

de Florianópolis,

Prefeitura de

Florianópolis. Avenida

Professor Henrique

da Silva Fontes, 6100.

Florianópolis, SC,

Brasil. 88036-700.

danielabliz@

yahoo.com.br

(b) Programa de

Pós-Graduação em

Saúde Coletiva

Departamento de

Saúde Pública, Centro

de Ciências da Saúde,

Universidade Federal

de Santa Catarina.

Florianópolis, SC, Brasil. marverdi@hotmail.com
} 


\section{Introdução}

A Política Nacional de Humanização (PNH) é norteada por bases ético-políticas como a valorização das dimensões subjetiva, coletiva e social em todas as práticas de atenção e gestão no Sistema Único de Saúde (SUS), fortalecendo o compromisso com os direitos dos cidadãos, o trabalho em equipe multiprofissional, a construção de redes cooperativas e de autonomia e protagonismo dos sujeitos individuais e coletivos ${ }^{1}$. A PNH atravessa as diferentes ações e instâncias do SUS e tem como objetivo provocar inovações nas práticas gerenciais e nas práticas de produção de saúde, propondo o desafio de superar limites e experimentar novas formas de organização dos serviços e novos modos de produção e circulação de poder ${ }^{2}$.

A humanização, entendida como estratégia de interferência nas práticas de saúde, tem na metodologia do apoio institucional sua principal estratégia de mobilização de diferentes atores (gestores, trabalhadores e usuários) em torno da tarefa de construção de projetos cogeridos que atendam às necessidades dos diferentes grupos de interesse ${ }^{3}$.

A partir de 2006, a PNH apostou na sua capilarização via processos de formação com o objetivo de fortalecimento e efetivação do SUS. Esses processos são fundamentados na inseparabilidade entre formação e intervenção. Foi a partir daí que surgiu a proposta do Curso de Formação de Apoiadores em Humanização da Atenção e Gestão do SUS.

Como proposta pedagógica, os participantes construíram e implementaram planos de intervenção, que consistiam em planos orientadores dos processos de reorganização de práticas/gestão nos serviços em seus respectivos locais de trabalho.

No território de Santa Catarina, a iniciativa de formação de apoiadores da $\mathrm{PNH}$, com essa estrutura, foi pactuada e desenvolvida em 2009. A estratégia visou formar sujeitos com capacidade de propor intervenções nas práticas de atenção e de gestão nos serviços de saúde, buscando fomentar e consolidar processos de mudanças com base no referencial da PNH.

Como questão relevante nesse processo de formação de apoiadores da PNH em Santa Catarina, pode-se apontar a concentração da escolha dos apoiadores na diretriz cogestão para o desenvolvimento de seus planos de intervenção. Chamou a atenção o fato de 29 dos sessenta apoiadores que estavam fazendo o curso pautarem a temática da gestão como demanda de intervenção, visando à transformação das práticas vigentes.

Segundo Campos, não há como haver projeto de humanização sem que se leve em conta o tema da democratização das relações interpessoais e, em decorrência, da democracia em instituições. No SUS, a humanização depende, portanto, do aperfeiçoamento do sistema de cogestão, de sua extensão para cada serviço e para as relações cotidianas 4 .

Considerando a importância de se aprofundar o conhecimento em torno dessa questão, o presente estudo buscou analisar os novos modos de gestão experimentados pelos apoiadores institucionais formados no curso da Política Nacional de Humanização em Santa Catarina, no ano de 2009, a partir da implementação dos planos de intervenção.

\section{Percurso metodológico}

Trata-se de um estudo qualitativo, com design exploratório-descritivo, realizado junto aos apoiadores que participaram do Curso de Formação de Apoiadores da PNH do estado de Santa Catarina em 2009.

Ao longo de sete meses, totalizando duzentas e trinta horas, o curso envolveu sessenta profissionais oriundos de 28 diferentes municípios do Estado. A organização do curso baseou-se em quatro eixos programáticos: O SUS e a PNH, princípios e estratégias; O apoio institucional e análise de demanda em saúde; Dispositivos e ferramentas de intervenção e HumanizaSUS e as redes sociais. Como estratégia metodológica, os apoiadores organizaram-se em sete Unidades de Produção (UPs), que são grupos de, em média, dez apoiadores, de uma mesma região, que buscam, por meio desse arranjo, a produção de grupalidade. 
Como sujeitos de pesquisa selecionaram-se aqueles apoiadores que optaram por trabalhar a diretriz cogestão no plano de intervenção elaborado ao longo do curso. Como critérios de inclusão no estudo foram utilizadas as condições de ter finalizado o curso, ter elaborado o plano de intervenção e aceitar participar do estudo. Além desses critérios, considerou-se importante diversificar as experiências de intervenção desenvolvidas no território de Santa Catarina, selecionando aleatoriamente um apoiador de cada UP para participar do estudo, totalizando assim sete apoiadores que foram efetivamente os sujeitos desta pesquisa. Esses sujeitos foram identificados com codinome de flores para garantir a confidencialidade de suas identidades.

A coleta de dados se deu em duas etapas: pesquisa documental e realização de entrevistas. A etapa documental contemplou a realização de um levantamento situacional dos sete planos de intervenção dos apoiadores, que na sequência foram entrevistados a partir de um roteiro prévio e semiestruturado com perguntas abertas visando aprofundar aspectos que os planos de intervenção não haviam contemplado. O fechamento amostral se deu por saturação teórica. Os dados foram armazenados e organizados por intermédio do software de organização e análise de dados qualitativos Atlas.ti 7.1®. A análise foi realizada por meio do método hermenêutico dialético, de acordo com proposta de Minayo ${ }^{5}$.

Para garantir os aspectos éticos no desenvolvimento de pesquisa com seres humanos, as Diretrizes e Normas da Resolução n 196/96 do Conselho Nacional de Saúde do Ministério da Saúde (CNS/MS) nortearam o desenvolvimento deste estudo. O projeto foi aprovado pelo Comitê de Ética e Pesquisa com Seres Humanos da Universidade Federal de Santa Catarina.

\section{Da motivação para trabalhar cogestão aos efeitos no território}

O processo analítico permitiu identificar três categorias temáticas que foram discutidas a seguir à luz do referencial teórico de Gastão Wagner de Sousa Campos e da Bioética: Motivações para trabalhar cogestão, Experimentando a cogestão e Efeitos da intervenção.

\section{Motivações para trabalhar cogestão}

A distância entre a vivência de um modelo de gestão tradicional e a ideia de participação nas instâncias decisórias revelou-se um aspecto fundamental na problematização das práticas de gestão nos processos de trabalho dos apoiadores. A gestão tradicional vivenciada pelos trabalhadores no cotidiano dos serviços de saúde, revelada no modo de gerenciar o trabalho em saúde segundo regras tayloristas, normatização burocrática, supervisão direta e controle de horário, mostrou-se um elemento limitador da ideia de participação em espaços decisórios. Ao mesmo tempo a cogestão foi vislumbrada pelos trabalhadores como sendo a possibilidade de mudança dessa situação já instituída.

O SUS ainda convive com uma série de limitações com relação às condições concretas de trabalho que levam à precarização, à exploração e à desvalorização do trabalho, e com relação aos modos de organização do processo de trabalho, em geral tendentes à expropriação dos trabalhadores dos processos decisórios ${ }^{6}$. Os apoiadores entrevistados revelaram que esses problemas foram manifestados pelos trabalhadores ao se reportarem sobre seu cotidiano:

"Mas os funcionários sim, a gente escutava muito isso: A direção vai e toma uma decisão, põe em prática e diz o que a gente tem que fazer e pronto e a gente não tem o direito nem de opinar". (Orquídea)

"Ainda há poucos espaços de reflexão nas instituições de saúde que possibilitem pensar, fazer e discutir no coletivo os processos de trabalho". (Lírio)

A não participação dos trabalhadores em processos decisórios revela-se como reflexo do modelo tradicional de gestão, ou seja, da racionalidade gerencial hegemônica que ao reduzir os espaços de reflexão e participação dificulta a autonomia dos sujeitos. 
Portanto, pode-se observar que nos serviços de saúde ainda convive-se com reflexos da Teoria Geral da Administração, o taylorismo em particular, que preconiza a administração de pessoas como se elas fossem instrumentos, coisas ou recursos destituídos de vontade ou de projeto próprio.

Comando e controle pressupõe concentração de poder. Dentre os princípios da teoria taylorista destaca-se a separação entre o trabalho intelectual e o trabalho de execução e também a centralização do poder de planejar e de decidir ao "chefe", buscando assim, limitar a autonomia e a iniciativa do trabalhador ${ }^{7}$. Esta retirada do poder do trabalhador é um dado concreto evidenciado nas manifestações dos apoiadores:

"Porque as reuniões, eram assim, não era roda de conversa, a coordenação vinha, com uma série de papéis, informes, e era assim, tum tum tum, era isso, terminava a reunião, todo mundo ia embora. Ninguém conversou sobre nada, sobre o que acontece no dia a dia, sobre as relações de trabalho, nada era feito". (Lírio)

Esses modos de gerir e se relacionar não favorecem o estabelecimento de relações democráticas ou de convivência solidária e retira dos profissionais a capacidade de decidir sobre o seu processo de trabalho. Ao contrário, exacerba a alienação do trabalhador, pois todo o poder é passado aos gerentes, que mediante vários mecanismos, controlam e determinam o trabalho cotidiano dos trabalhadores. Assim, a gestão nos moldes tayloristas assenta-se, portanto, sobre as necessidades de conservar alienada a maioria dos trabalhadores.

Esses depoimentos sugerem que os trabalhadores vivenciam dificuldades no cotidiano do seu trabalho no que se refere aos processos decisórios. Acerca da autonomia, Campos alerta que a maioria dos métodos de gestão tende a reduzir a autonomia do ser humano em suas produções, incluindo a produção de saúde, ao utilizarem estratégias tanto diretas quanto indiretas para o controle do trabalho humano ${ }^{8}$.

A decisão autônoma dos trabalhadores é importante no exercício do trabalho em saúde - trabalho vivo em ato - por ser uma práxis. A atividade humana em que o saber prévio requer, do agente da ação, reflexão, deliberação ou escolha em ato, marca a práxis. Ou seja, na práxis, o agente da ação “deverá considerar o contexto singular em que a ação se realiza: outros sujeitos envolvidos, valores, circunstâncias históricas, etc" ${ }^{8}$ (p. 2340). Esse é o modo como deve ser exercido o trabalho em saúde e, por isso, dependente de trabalhadores com significativo grau de autonomia.

Entretanto, os apoiadores, apesar de conviverem e serem submetidos a esse modelo tradicional de gestão que exclui o trabalhador dos processos decisórios, reconhecem outra possibilidade de gestão do trabalho, a cogestão.

Cogestão significa a inclusão de novos sujeitos nos processos de gestão. Assim, ela é exercida por um conjunto mais ampliado de sujeitos que compõem a organização, assumindo-se o predicado de que todos são gestores de seus processos de trabalho. O prefixo "co", nessa perspectiva, indica para o conceito e a experimentação da gestão um duplo movimento: a adição de novas funções e adição de novos sujeitos ${ }^{3}$.

A ideia de que gestão é uma tarefa coletiva, sistemas de cogestão, e não somente uma atribuição de minorias poderosas e especialistas, portanto, consiste numa crítica a maneira dominante sobre os modos de analisar e gerir o trabalho. O exercício do cogoverno depende da produção simultânea de espaços coletivos que cumpririam três funções básicas: uma clássica de planejar o processo de trabalho, outra política tendo a cogestão como uma forma de alterar as relações de poder e a terceira seria a função pedagógica e terapêutica, que é a capacidade que os processos de gestão têm de influir sobre a constituição de sujeitos ${ }^{3}$.

Os trabalhadores reconhecem a diretriz cogestão como sendo essencial para provocar e promover mudanças, de forma a gerar democratização nas instituições.

“Nesse espaço, é importante possuir um ambiente estruturado fisicamente como uma sala de reuniões que possibilite o trabalho em roda, mas também ou mais importante é haver um 
espaço que estimule o desenvolvimento da capacidade de reflexão e autonomia de ação do sujeito enquanto corresponsável pela viabilização da gestão e atenção à saúde". (Cravo)

Todos esses problemas apontados pelos trabalhadores que estão no exercício de atividades fins e, também, os que ocupam lugares na gestão são complexas. Para o enfrentamento dessas realidades, a PNH aponta um conjunto de diretrizes, cuja experimentação coloca sujeitos em contato e em relação para que, de forma coletiva e tomando por referências princípios ético-políticos e acúmulos do SUS, que dá certo, construam soluções singulares ${ }^{6}$.

Percebe-se, a partir das falas dos sujeitos, que um dos desafios enfrentados no cotidiano das práticas de saúde reside exatamente nos modos verticalizados de gestão. Tal separação tem reafirmado práticas que concebem a gestão como reduzida à administração e centrada na figura do gestor. Desse modo, há aqueles que planejam e pensam a ordenação do sistema de saúde, os gestores, e aqueles que executam e operacionalizam os planejamentos, os trabalhadores.

Diante de todas as fragilidades levantadas, do modo de gestão tradicional vivido pelos trabalhadores que lhes exclui a possibilidade de participação e de exercer autonomia no dia a dia de trabalho, os apoiadores após discussão com a equipe optaram trabalhar a diretriz cogestão, por ser a oferta disponível no serviço onde estavam inseridos no momento do curso, como maneira de proteger o serviço de saúde contra instabilidades externas, como a troca de gestão, por exemplo, e por acreditarem que trabalhando com a cogestão seu processo e trabalho e gestão seriam facilitados.

"Foi preciso ver na roda quais as necessidades do serviço. O grupo trouxe três possibilidades de intervenção, a primeira delas foi Cogestão, o que já vinha aparecendo desde a primeira roda". (Lírio)

“Porque eu me sentia sozinha. Porque é complicado, uma pessoa de uma equipe que tá na gestão fazer um curso de formação com toda aquela bagagem, aquele conteúdo, aquela coisarada que a política te traz e tu chegar, voltar pro teu município e tu te vê sozinha para botar as coisas em prática". (Gloriosa)

Lembrando que as escolhas e decisões de um trabalhador conformam suas ações para uma práxis que, a depender de como o trabalho e o contexto onde é desenvolvido são compreendidos, poderá ser consciente, reflexiva, crítica, criativa, emancipadora, ou subordinada somente a padrões e normas, não criadora, tendente à desvalorização da subjetividade dos envolvidos, ou seja, uma práxis alienada, acerca da produção de saúde. Em outras palavras, o fato de os trabalhadores não terem domínio quanto ao seu processo de trabalho, pode estar contribuindo para que eles estejam exercendo uma práxis cotidiana-conservadora. A partir de um olhar bioético, não se sentir como parte de algo, como dos espaços decisórios e reconhecer outra possibilidade caracteriza um conflito vivenciado pelos trabalhadores, mas que felizmente refletiu em proposição de mudanças 9 .

A partir daí, com os problemas levantados e discutidos com a equipe, com conhecimento adquirido no curso e a vontade de promover mudanças, iniciou-se a experimentação da cogestão, conforme será discutido na categoria temática apresentada a seguir.

\section{Experimentando a cogestão}

Esta categoria refere-se aos dispositivos utilizados para exercício da cogestão e às facilidades e dificuldades encontradas pelos apoiadores durante o processo de construção desses espaços de cogestão.

A diversidade dos locais nos quais se desenvolveram as intervenções se mostrou relevante para a ampliação da interlocução entre os apoiadores. Os sujeitos entrevistados eram vinculados a instituições diversas como hospitais de grande porte, escola de formação em saúde, centros de saúde, além de secretarias municipais de saúde. 
Dentre os dispositivos escolhidos para efetivar a diretriz da cogestão o Grupo de Trabalho em Humanização (GTH) foi proposto por quatro dos sete apoiadores entrevistados, conforme exemplificado no relato a seguir.

"Formar um GTH como forma de incluir os três grupos de atores (gestão, trabalhadores e usuários), de abordar a corresponsabilização, cogestão e gestão participativa, talvez seja uma possibilidade". (Jasmim)

O GTH é um dispositivo sugerido pela PNH para o SUS, com o objetivo de intervir na melhoria dos processos de trabalho e na qualidade da produção de saúde para todos. Tem como atribuições além de difundir os princípios norteadores da $\mathrm{PNH}$, levantar os pontos críticos do funcionamento de cada serviço e sua rede de referência, promover o trabalho em equipes multiprofissionais, estimulando a transversalidade e a grupalidade; propor uma agenda de mudanças e incentivar a democratização da gestão $^{10}$.

Outros dispositivos, como fluxograma descritor e cogestão no processo avaliativo de um curso, foram utilizados pelos apoiadores:

“Entendendo que o fluxograma descritor é uma forma clara e visível da descrição do processo de trabalho que se revela em um mundo extremamente complexo e que norteia as ações de saúde para um rumo previamente submetido a análises de um coletivo de profissionais e gestores, se observou a necessidade de iniciar os trabalhos de cogestão e coparticipação reorganizando os fluxos do processo de trabalho em saúde". (Cravo)

“Fazendo algumas reflexões referente à importância da gestão para organização do trabalho e as formas como acontecem as relações no mundo do trabalho ou seja, hierárquica, vertical, sem um processo de comunicação horizontal, nos propusemos a discutir a cogestão enquanto diretriz e o Acompanhamento Avaliativo enquanto método de avaliação como importantes instrumentos para o desenvolvimento da intervenção na formação aos cuidadores de pessoas idosas". (Rosa)

Os apoiadores utilizaram o método da roda para colocar em prática suas propostas de cogestão. O método da Roda, proposto por Campos, é entendido como um espaço democrático, um modo de operacionalizar a cogestão, onde de fato se analisem problemas e se tomem deliberações ${ }^{3}$.

Entretanto a grande demanda de serviços, tanto na atenção básica quanto em emergências, foi um dificultador levantado pelos apoiadores que lá implementaram a cogestão, como fator impeditivo à parada para a realização da roda:

"O fato de estar inserida em uma emergência também deve ser considerado como um desafio para o desenvolvimento da função apoio, pois as coisas nesse setor acontecem de modo muito rápido e imprevisível. Portanto, tornam-se difícil fazer programações como as pausas necessárias para a análise e discussões das situações vivenciadas, ou seja, as rodas". (Margarida)

O método da roda objetiva aumentar a capacidade de compreensão e de intervenção dos sujeitos sobre o mundo e sobre si mesmo, contribuindo para instituir processos de construção de sociedades com grau crescente de democracia e de bem-estar social.

Criar espaços de democracia ampliada, processos produtores de sujeitos-cidadãos, grupos capazes de impor resistência às determinações adversas do meio em uma sociedade injusta e contraditória é um desafio. E a partir do momento em que os apoiadores experimentaram na prática a cogestão tanto facilidades como dificuldades foram encontradas por eles.

A maior parte dos apoiadores relatou a resistência da equipe, num primeiro momento, como uma das dificuldades encontradas possivelmente pela construção do plano de intervenção não ter sido 
coletiva, pela maioria dos apoiadores. Observa-se que se repetiu mais uma vez a dicotomia existente entre quem planeja e quem executa:

"Cabe ressaltar que a intervenção, por ainda ser uma proposta inicial e, portanto inacabada, não foi construída coletivamente". (Margarida)

"Inicialmente, houve resistências por parte de colegas em formar as grupalidades, desse deslocar de sua zona de conforto e colocar na roda situações que transformaria aquela rotina que eram acostumados". (Cravo)

Percebe-se aí um desafio significativo e ainda não superado: a dicotomia entre o planejar e o executar. Tal situação pode ter sido provocada pelas diferenças entre o apoiador e os demais trabalhadores, uma vez que a vivência e motivação adquiridas ao longo do curso provocaram mudanças subjetivas ainda não conhecidas dos outros trabalhadores. Ainda que a PNH tenha em sua concepção a inseparabilidade entre teoria e prática, planejar e executar, pensar e fazer, e trabalhasse com o objetivo de integrar e compartilhar os diversos saberes, os apoiadores vivenciaram relações de poder que se instalaram entre o apoiador e os demais membros da equipe. Mas mesmo assim, a maioria dos apoiadores percebeu e enfrentou essa dificuldade, criando estratégias e reformulações com o objetivo de envolver todos os trabalhadores de maneira que essa fragmentação não permanecesse.

A gestão no serviço público, em geral, condicionada pela articulação político-partidária contribui para o trabalho centralizado na figura do gestor principal. E assim as equipes continuam vivenciando formas burocráticas e autoritárias, com baixa participação dos trabalhadores na gestão. Com a rotatividade político-administrativa que ocorre continuamente, torna-se imprescindível que $o$ trabalhador assuma o protagonismo de seus processos de trabalho, para que não seja capturado a cada mudança de gestor ${ }^{11}$.

A resistência do gestor para a efetivação da cogestão gerou grandes dificuldades e conflitos.

"Teve um enfrentamento com a gestão. Então isso começou a ter um choque de ideias muito grande, então foi onde a gente começou a perceber que a gestão, a nova, essa nova gestão central, tornou-se um dificultador do trabalho". (Margarida)

Entretanto, nos casos em que havia apoio por parte dos gestores imediatos ou chefia, facilidades foram levantadas, como se exemplifica na citação do apoiador:

“Eu acho que inicialmente teve bastante facilidade, porque era uma coisa que vinha do próprio governo querer implantar a humanização, no município. O gestor queria e a proposta era implantar, então teve facilidade. Facilidade também para fazer o curso. Conhecendo a realidade local podemos promover processos de mudança". (Jasmim)

Espaço de democracia, criado com reuniões periódicas, onde o grupo seria a instância de deliberação como um colegiado que cumpre uma função integradora, tentando articular aquilo que a descentralização do poder tende a opor ou a fragmentar é um desafio. Entretanto, para que esses espaços sejam criados, espera-se que o gestor da instituição esteja motivado para essa mudança, caso contrário, toda e qualquer tentativa será frustrada ${ }^{3}$.

O vínculo dos apoiadores com a equipe na qual estavam inseridos foi uma facilidade apontada por eles, o que favoreceu o envolvimento da equipe de trabalhar a cogestão, de desenvolver e participar das rodas.

"Eu acho que a facilidade que eu tive em relação a toda uma formação e experiência que eu já tinha na atenção básica de conhecer aquelas equipes, aqueles profissionais. Então, eu acho que essa foi uma facilidade". (Margarida) 
Em contrapartida, a fragilidade do vínculo empregatício que gera a rotatividade dos profissionais e, consequentemente, a quebra no vínculo entre a equipe e da mesma forma a continuidade do espaço coletivo criado foram condicionantes desfavoráveis levantados. Dois apoiadores não conseguiram implementar a proposta de cogestão devido à transferência do local de trabalho.

“É um dificultador sim, porque, por exemplo, os trabalhadores que são contratados, alguns ficam dois anos no mesmo lugar, mas alguns não, ficam um mês, seis meses, enfim, ficam rodando, né, e isso é muito difícil... Eles até costumam dizer assim, quando a pessoa tá pegando o jeitinho, aí tem que sair". (Lírio)

“Todavia, mesmo com a certeza de continuar inserida no SUS, não me sentia segura para dar continuidade nas atividades propostas pelo curso como, por exemplo, a roda com os demais trabalhadores no novo local de trabalho. Acredito que tal fato se deu devido à falta de vínculo com os recém colegas de trabalho". (Margarida)

A fixação do profissional, mediante um vínculo empregatício estável, pode favorecer a emancipação e a participação em espaços decisórios.

Apesar de o desafio central de qualquer governo que se pretenda democrático seja administrar as diferenças e choques entre distintos desejos e interesses e não ignorá-los, negá-los e reprimílos em nome de uma suposta objetividade, não foi o desfecho encontrado por dois dos apoiadores entrevistas, mas sim o contrário. Percebeu-se que os trabalhadores que se posicionavam mais firmemente, encontravam sérios problemas. Por isso, muitos tensionamentos e conflitos foram vivenciados pelos apoiadores.

"Ao colocar em prática. Aí pegou. Porque a gente desvendava né... Todos os problemas, tudo o que faltava... Então, tudo isso começou a aparecer e começou a ter muito atrito, muito atrito. Assim ó, o secretário chegou um momento que ele se absteve de conversar comigo. Então eu não tinha chefe mais. E aí a minha chefe na época disse que não queria mais ser chefe, que ela não queria mais, porque eu era a pessoa que levava os problemas entendeu? Bem na época que eu fui mandada embora". (Jasmim)

É importante considerar que sempre haverá antagonismos e conflitos entre diretores, coordenadores, trabalhadores e usuários. Na verdade a cogestão não se propõe a eliminar esses conflitos e contradições. Ao contrário, tratar-se-ia de, ao admitir a inevitável existência dessas polaridades, de se criar espaços onde pudessem ser explicitadas e trabalhadas, considerando-se, sempre, os vários interesses e, portanto, as várias racionalidades envolvidas.

A cogestão é uma diretriz estruturante da $\mathrm{PNH}$ e sua experimentação revela disputas de saber, de poder e tensionamentos interpessoais e intergrupais. Entretanto, o exercício da coanálise, da codecisão e da corresponsabilização é base do trabalho em saúde, portanto, é imprescindível para a reformulação dos modos de gestão tradicional11.

Percebe-se que construir esses coletivos de cogestão tem sido um desafio constante, processo por vezes difícil e desencadeador de tensionamentos; mas, por outro lado, proporciona um olhar crítico, formado a partir das questões e demandas apresentadas, mais que a soma dos olhares entre gestores, trabalhadores e usuários ${ }^{11}$.

\section{Efeitos da intervenção}

Esta categoria discute os efeitos da intervenção no território resgatando os avanços e desafios da cogestão. A intervenção contribuiu para alguns avanços, como a criação de espaços coletivos para a gestão, entretanto, desafios como a concentração de poder e a limitação da participação do trabalhador dos espaços decisórios ainda permanecem. 
Para viabilizar esse novo modo de gestão, foram criados horários para encontros periódicos do coletivo com tempo para reuniões ordinárias dentro do período normal de trabalho, ou seja, o planejamento e a reflexão fazendo parte do processo habitual de trabalho. Nesses espaços, a equipe discute necessidades de saúde, divisão de tarefas, elaboração de planos e faz reflexão acerca de seu processo de trabalho de maneira que mudanças possam ser sugeridas. E este é um efeito emancipatório, a ampliação da autonomia de uma pessoa depende sempre da ampliação de sua capacidade de compreender e de agir sobre o mundo e sobre si mesma.

"A maior conquista que percebo, e que faz com que a instituição se aproxime mais das propostas da $\mathrm{PNH}$, é a inclusão dos trabalhadores em algumas decisões no processo de gestão e atenção da saúde através da roda". (Cravo)

"O processo de construção da gestão participativa e cogestão estão em constante evolução e amadurecimento. Em alguns aspectos evoluímos muito, como é o caso da reestruturação dos fluxos de funcionamento da instituição, o que já possibilitou reordenação dos serviços reduzindo as filas de esperas para atendimento". (Cravo)

Esses espaços coletivos são entendidos como a construção de lugares e de tempos por meio dos quais as equipes, de fato, têm interferido nos processos produtivos. A cogestão realizada em espaços coletivos é um caminho para a democratização. Aposta-se na possibilidade de se instituírem sistemas de cogestão que produzam tanto compromisso e solidariedade com o interesse público, quanto capacidade reflexiva e autonomia dos agentes da produção ${ }^{3}$.

Realizar o percurso sugerido, da cogestão, não é uma tarefa simples. Ao contrário, depende de apoio externo e do estabelecimento de uma série de condições objetivas, entre elas a possibilidade de se organizarem espaços protegidos para a reflexão como as rodas; depende ainda da substituição da repressão como método para resolver conflitos, por processos de negociação entre interesses e perspectivas distintas. O método da roda se propõe a contribuir para a democratização das instituições, mas, paradoxalmente, depende bastante da instituição de espaços democráticos.

Avanços podem ser vistos conforme as falas dos apoiadores:

"Algumas conquistas/transformação que se concretizou já andam em patamares avançados, como é o caso do espaço para as rodas, e os níveis de discussão que ocorre nelas vem melhorando a cada encontro". (Cravo)

"Na época, foi criado o conselho de saúde, porque não tinha aqui". (Lírio)

“Então, o GTH foi incluído em um núcleo que trabalha educação permanente e humanização. E está bem legal...". (Gloriosa)

Um sistema de cogestão depende da construção ampliada de "capacidade de direção" entre o conjunto das pessoas de um coletivo e não somente entre sua cúpula. Capacidade de direção é a habilidade e a potência para compor consensos, alianças e implementar projetos. É também uma aptidão a ser socialmente construída, já que cogovernar é uma tarefa inerente a todos os membros de uma equipe de trabalho.

Entretanto, ainda observa-se a concentração de poder, ou seja, permanecem ainda espaços onde os trabalhadores não participam. Ou ainda, em espaços coletivos os trabalhadores ainda sentem medo de participar.

"O Colegiado Gestor: colocamos este em prática através da cogestão da Secretaria de Saúde. O Secretário e os Diretores de cada setor reúnem-se em Colegiado continuamente". (Cravo) 
"Tinha liberdade, mas aí dentro dessa liberdade tinha uma dificuldade também que era assim ó, a gente estava sentada em roda discutindo e eu sentia que tinha alguns profissionais que tinham medo ou receio de falar". (Gloriosa)

Campos $^{12}$ afirma que o interesse particular de grupos ou de pessoas em concentrar poder tem predominado sobre o interesse coletivo de se ter governos com capacidade para assegurar o bemestar. Algumas organizações conseguiram democratizar-se. E em todas elas constatou-se uma combinação de concentração de poder e, portanto, certo grau exacerbado de controle sobre o sentido de trabalho em saúde, com reforma de organogramas e das relações de poder, objetivando dotá-las de maior horizontalidade. Em diversas experiências, houve poder concentrado de governo empurrando, estimulando, quebrando resistências, em um movimento de cima para baixo, de maneira a assegurar o prosseguimento da democratização para que com o tempo, haja uma inversão de tendência, ou seja, a base de trabalhadores e de cidadãos ligados aos serviços pudesse autoestimular o prolongamento dessas experiências.

Portanto, haveria de fato, entre essas duas diretrizes, certo paradoxo, pois para se democratizar, exige-se concentração de poder. Alguém como governo, movimento, grupo de trabalhadores que banque o processo ${ }^{13}$.

A construção de sociedades e de instituições democráticas depende da política em seu sentido mais amplo. Movimentos sociais, amplas coalizões, blocos históricos, alianças entre classes, lutas entre interesses econômicos e ideológicos. Ou seja, alterar a relação entre dominantes e dominados. $\mathrm{O}$ poder como resultado e como relação ${ }^{3}$.

Observe-se que o exercício do trabalho, segundo a lógica da práxis, depende de sujeitos trabalhadores com importante grau de autonomia e de responsabilidade com o outro e com as instituições. A racionalidade gerencial dominante aposta em outra direção, buscando, em suas várias vertentes, restringir as situações em que o processo de trabalho depende de decisão autônoma dos trabalhadores ${ }^{8}$.

Conforme Beauchamp e Childress ${ }^{14}$, a autonomia é entendida como a capacidade de deliberar e escolher livremente. Para os autores, a ação autônoma depende das seguintes condições: primeiro, agir com intencionalidade (ser agente); segundo, agir com conhecimento de causa (entendimento); e por último, sem influências controladoras que determinem sua ação (com liberdade). A primeira condição, a intencionalidade, não permite graduação, ou seja, em uma ação autônoma, há intencionalidade ou não; entretanto, as outras duas condições podem estar presentes em maior ou em menor grau, sem a exigência de "um entendimento pleno ou uma completa ausência de influência".

Portanto, a autonomia também depende de "condições externas ao sujeito", mesmo que esse tenha contribuído na produção de tais circunstâncias. Ou seja: "Depende da existência de leis mais ou menos democráticas. Depende do funcionamento da economia, da existência de políticas públicas, de valores veiculados por instituições e organizações. Depende da cultura em que está imerso" ${ }^{15}$ (p. 671).

Assim, pode-se dizer que os trabalhadores enfrentam muitas limitações no exercício da autonomia no seu processo de trabalho. Em resumo, o tripé de sustentação da autonomia - ser agente, agir com entendimento e com liberdade, encontra-se desestabilizado no processo de trabalho dos apoiadores ${ }^{14}$.

\section{Considerações finais}

Os movimentos disparados pelas intervenções dos apoiadores nos serviços com relação à cogestão foram importantes para promover mudanças em processos anteriormente cristalizados. Os processos de intervenção possibilitaram criar estratégias para enfrentar desafios, tais como: articulação de iniciativas de humanização do SUS, até então isoladas; mapeamento do processo de trabalho nos serviços de saúde, identificando pontos críticos e elaborando estratégias de superação; criação de rodas de conversa incluindo trabalhadores, gestores e usuários para reflexão acerca do processo de trabalho e da assistência nos serviços de saúde e organização de fluxos de atendimento. Os planos de intervenção dispararam rodas de conversa nos serviços, interferindo nos modos de gestão e atenção 
instituídos. Os apoiadores indicaram que o curso lhes permitiu ampliar suas caixas de ferramentas, qualificando ações já disparadas, ampliando a capacidade de análise dos profissionais da saúde.

Pode-se dizer, a partir dos discursos feitos pelos apoiadores formados no curso, que essa ação se constituiu como oportunidade de problematização da experiência de trabalho vivenciada enquanto profissionais da saúde, uma vez que privilegiou o compartilhamento de experiências entre esses atores, e destes com os profissionais de saúde atuantes nos serviços em que as intervenções se deram, e os usuários do SUS.

Pode-se observar que a cogestão de coletivos organizados para a produção depende de vontade política e de condições objetivas. A proposta é trabalhar sujeitos e instituições. Um movimento interferindo e modificando o outro.

Movimentos inovadores e criativos por parte dos trabalhadores já estão em curso, em princípio não precisando ser estimulados, mas fortalecidos enquanto potência. Entretanto, há de ressaltar que, no trabalho atual em saúde, vivem-se pressões e controle que têm oprimido, desvalorizado e desestimulado os movimentos e a potência dos coletivos.

Considerando que os conflitos éticos são inerentes às relações humanas, eles estão presentes nas relações estabelecidas entre os trabalhadores e gestores. A existência dos conflitos éticos nessas relações não pode ser ignorada, pois eles podem eclodir sob as mais variadas formas, algumas inclusive, comprometendo os princípios do SUS. Para Berlinguer ${ }^{16}$, os conflitos éticos dizem respeito a "interesses materiais e argumentos morais diversos" (p. 128) e, o único modo de superar ou compor os conflitos é reconhecê-los. Por isso, a importância de se revelar os conflitos éticos no processo de trabalho, pois abre a possibilidade dos apoiadores e gestores refletirem sobre esses conflitos e assim, adotarem ações capazes de mudar comportamentos cristalizados e estimular a busca de resultados melhores ${ }^{16}$.

A reflexão até aqui desenvolvida indica que a construção de espaços coletivos é um modelo de gestão que possibilita e favorece, mas não garante a autonomia dos sujeitos. Acredita-se que ambas as pretensões dependem de trabalhadores que reflitam e tomem decisões, ou seja, depende de sujeitos éticos e políticos.

\section{Colaboradores}

Os autores trabalharam juntos em todas as etapas de produção do manuscrito.

\section{Referências}

1. Ministério da Saúde. Secretaria Executiva. Política Nacional de Humanização: documento base para gestores e trabalhadores do SUS. Brasília (DF): MS; 2004.

2. Ministério da Saúde. Secretaria de Atenção à Saúde. Cadernos HumanizaSUS: formação e intervenção. Brasília (DF): MS; 2009.

3. Campos GWS. Um método para Análise de Coletivos. 3a ed. São Paulo: Hucitec; 2007.

4. Campos GWS. Humanização na Saúde: um projeto em defesa da vida. Interface (Botucatu). 2005; 9(17):389-406. 
5. Minayo MCS. Pesquisa social: teoria, método e criatividade. 3a ed. Petrópolis: Vozes; 2004.

6. Pashe DF. Política Nacional de Humanização como aposta na produção coletiva de mudanças nos modos de gerir e cuidar. Interface (Botucatu). 2009; 13(1):701-8.

7. Taylor WF. Princípios da administração científica. São Paulo: Atlas; 1960.

8. Campos GWS. Cogestão e neoartesanato: elementos conceituais para repensar o trabalho em saúde combinando responsabilidade e autonomia. Cienc Saude Colet. 2010; 15(5):2337-44.

9. Ramos FRS. O processo de trabalho de educação em saúde. In: Ramos FRS, Verdi MIM, Kleba ME, organizadores. Para pensar o cotidiano: educação em saúde e a práxis da enfermagem. Florianópolis: Ed. UFSC; 1999. p. 16-61.

10. Ministério da Saúde. Secretaria de Atenção à Saúde. HumanizaSUS: documento base para gestores e trabalhadores do SUS. Brasília (DF): MS; 2008.

11. Mori ME, Oliveira OVM. Os coletivos da Política Nacional de Humanização (PNH): a cogestão em ato. Interface (Botucatu). 2009; 13(1):627-40.

12. Campos GWS. Efeito Paidéia e o campo da Saúde: reflexões sobre a relação entre o sujeito e o mundo da vida. Trab Educ Saude. 2006; 4(1):19-32.

13. Campos GWS. Subjetividade e administração de pessoal: considerações sobre modos de gerenciar o trabalho em equipes de saúde. In: Merhy EE, Campos RTO, organizadores. Agir em Saúde: um desafio para o público. 2a ed. São Paulo: Hucitec; 2006. p. 229-66.

14. Beauchamp TL, Childress JF. Princípios da Ética Biomédica. São Paulo: Loyola; 2002.

15. Campos RTO, Campos GWS. Co-construção de autonomia: o sujeito em questão. In: Campos GWS, Minayo MCS, Akerman M, Drumond Júnior M, Carvalho YM. Tratado de Saúde Coletiva. Rio de Janeiro: Hucitec; 2006. p. 669-87.

16. Berlinguer G. Bioética coditiana. Brasília (DF): UnB; 2004.

Calderon DBL, Verdi MIM. Cogestión y proceso de intervención de los apoyadores de la Política de Humanización Nacional. Interface (Botucatu). 2014; 18 Supl 1:859-70.

El objetivo del estudio fue analizar los cambios en el modo de gestión generados por el proceso de intervención de los apoyadores institucionales formados en el Curso de Apoyadores Institucionales para la Humanización de la Atención y Gestión del del Sistema Brasileño de Salud (SUS), realizado en 2009 en Santa Catarina, Brasil. Se trata de un estudio cualitativo con diseño exploratorio descriptivo. Los sujetos de la investigación fueron 7 apoyadores institucionales que trabajaron la directriz "cogestión" en sus planes de intervención. La recolección de datos fue por medio de investigación documental y entrevistas y los datos se analizaron utilizando el método dialéctico hermenéutico. Los referidos datos fueron clasificados y agrupados en categorías temáticas: "Motivaciones para trabajar la cogestión", "Cómo experimentar la cogestión" y "Efectos de la intervención." Los resultados mostraron que los movimientos causados por las intervenciones de los apoyadores en los servicios en lo que se refiere a la cogestión fueron importantes para promover cambios en procesos anteriormente cristalizados, aunque todavía son muchos los desafíos.

Palabras clave: Sistema Brasileño de Salud. Gestión en salud. Política Brasileña de Humanización. Cogestión.

Recebido em 05/12/13. Aprovado em 27/08/14. 